\title{
Expanded full thickness skin graft to repair scar and scar contractures: a descriptive case series
}

\author{
Nitin V. Ghag*, Aditya Aggarwal, Hardeep Singh, Sukhdeep Singh, Sanjay Mahendru, \\ Vimalendu Brajesh, Rakesh Khazanchi, Umang Kothari
}

Department of Plastic Surgery, Medanta - Medicity Hospital, Gurugram, Haryana, India

Received: 30 August 2020

Revised: 03 October 2020

Accepted: 13 October 2020

\author{
*Correspondence: \\ Dr. Nitin V. Ghag, \\ E-mail: ghagnitinv@yahoo.co.in
}

Copyright: (C) the author(s), publisher and licensee Medip Academy. This is an open-access article distributed under the terms of the Creative Commons Attribution Non-Commercial License, which permits unrestricted non-commercial use, distribution, and reproduction in any medium, provided the original work is properly cited.

\begin{abstract}
Management of deep burns/trauma scars has always been a challenge. Seven patients with burn/trauma scar were treated with expanded full thickness grafts (EFTSGs). In stage one, tissue expanders were implanted at the donor sites and expansion with saline was done as an out-patient for 4-5 months. In stage two, the scar was excised and secondary wound was repaired with EFTSGs. Total of 8 EFTSGs were harvested from various donor sites. After stage one there was good blood supply noted in all the expanded skin flaps. After stage two, EFTSGs survived in all; except for partial skin necrosis in the leg of one patient. The graft take were excellent in color-match, texture and elasticity. There was a significant improvement in function and aesthetic aspect in all the cases. EFTSGs is an effective solution to repair effectively scar and scar contractures due to excellent cosmetic and functional recovery.
\end{abstract}

Keywords: Expanded full thickness skin graft, Donor, Tissue expanders

\section{INTRODUCTION}

Secondary reconstruction of bodily deformities requires the use of autologous uninjured

tissues harvested as a free skin graft, a pedicled skin flap with/without fascia and/or muscle layer attached and microvascular free flaps. ${ }^{1}$ Frequent lack of autologous tissue demand a well-planned and organized method of replacement. ${ }^{2}$ Sequelae of burns become one of the best indications for progressive mechanical skin expansion by prosthesis to satisfy the skin requirement. ${ }^{3}$

\section{CASE SERIES}

Over two years (2013-2015), all the patients with postburn scar contracture and post-traumatic scar who reported to our outpatient department (OPD) and wanted surgical treatment were offered various treatment options among which post-expansion expanded full thickness skin grafts (EFTSGs) being one of them to cover the surgical defect. Selected patients underwent pre-operative routine work up and pre-anesthetic fitness was done. The type and the size of the expander were chosen keeping in mind the future post-surgical defect and the requirement to cover it. The surgery was divided in two stages-

\section{Stage one: tissue expander insertion and expansion}

Under general anaesthesia (GA), a previously selected tissue expander was inserted in the subcutaneous (SC) plane at the pre-selected donor site, the criteria for selection of donor site were skin color matching the recipient area, donor area without any previous scar. Appropriate prophylactic antibiotics were used. Incision to insert the expander was made on healthy skin. The pocket was created in the SC tissue and was kept larger than the tissue expander. Two layered closure was done to minimize risk of extrusion. Intra-operatively, tissue 
expander was expanded with normal saline (NS) amounting to $10 \%$ of the expander volume. The expander port was placed on a solid anatomical location away from the expander. Once the incision healed, expansion was started. Beginning from post-operative day 10 the tissue expander was subjected to gradual expansion with sterile $0.9 \%$ NS on an outpatient basis. Expansion was carried out every $5^{\text {th }}$ day for 4-5 months. End points of expansion during each sitting were - achieving $10 \%$ of the volume of expander, blanching at site of expansion and pain/discomfort noticed by the patient.

After serial expansions, the expanded skin was measured with the tape in its largest dimension and when the desired quantity of the skin was obtained, the expansion process was discontinued. Ten percent more than the required amount of the skin was taken into consideration, in order to compensate for the primary skin contraction which would occur after harvesting it as a EFTSGs. Donor site subjected to tissue expansion was examined carefully for its vascularity and any signs of inflammation/ infection. After stage one operation there was good blood supply noted in the entire expanded skin flap (Figure 1).

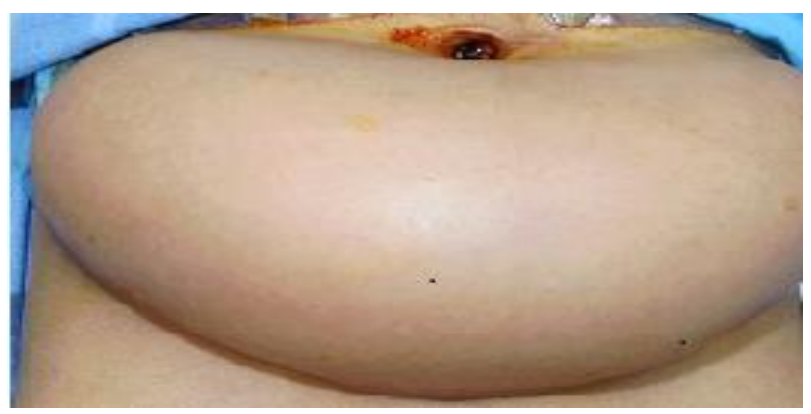

Figure 1: Stage one - completely expanded tissue expander in lower abdomen.

\section{Stage two: harvesting of EFTSGs and wound cover}

In this stage, scar was excised and secondary wound created. This secondary defect was measured and the required amount of skin was harvested as full thickness skin graft from the expanded donor site. Donor site could be primarily closed in all the patients (Figure $2 a$ and $b$ ).

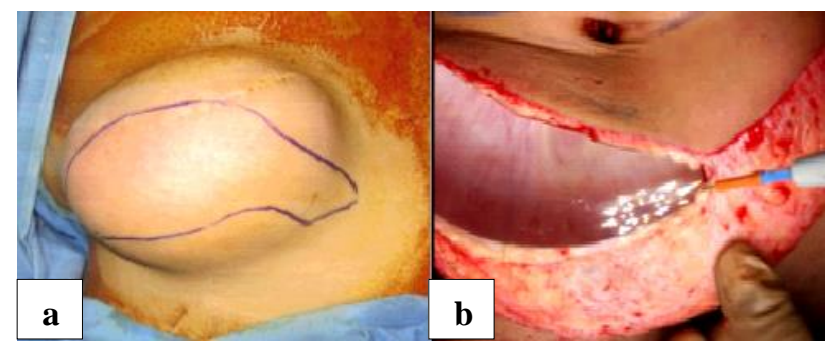

Figure 2: Stage two (a) template drawn over the expanded skin and (b) removal of tissue expander.

Total eight EFTSGs were used. A total of seven patients in which one of them underwent reconstruction of the post- burn scar of the right upper and lower extremity with 2 different sites EFTSGs.

Sixteen patients were seen with post-burn and posttraumatic scarring in outpatient. All were offered the various treatment of scar excision and reconstruction of the defect such as local flaps, split thickness skin graft, microvascular free flaps and EFTSGs. Seven agreed EFTSG and nine did not - primarily due to financial and time constraints and they were treated with the other said options. Patient age ranged from 5 years to 38 years with 3 males and 4 females; follow-up period varied from 6 months to 2 years.

In stage two, EFTSGs was harvested from the expanded region. Total seven EFTSGs were used. Grafts ranging in size from approximately $60 \mathrm{~cm}^{2}$ to greater than $700 \mathrm{~cm}^{2}$ were harvested from the expanded donor sites on lower abdomen and lower extremities. Among seven EFTSGs, three were used in upper extremity, one in lower extremity and three in the facial reconstruction. One patient underwent reconstruction of the post burn scar of the right upper and lower extremity with EFTSGs in two different sittings. The donor site was closed primarily in all cases. Post-operatively partial skin necrosis of approximately 6 $\mathrm{cm} 2$ in dimension was noted in the leg (recipient site of expanded FTSG) of one patient which later healed with debridement and regular dressings. In all other cases the EFTSGs take was good (Figure 3-5).

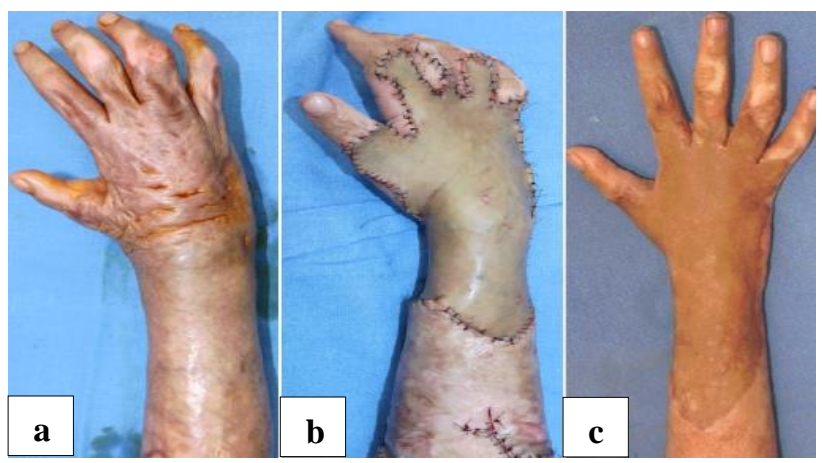

Figure 3: Results of post burn scar right hand (a) preoperative, (b) immediate post-operative and (c) 6 weeks post-operative.

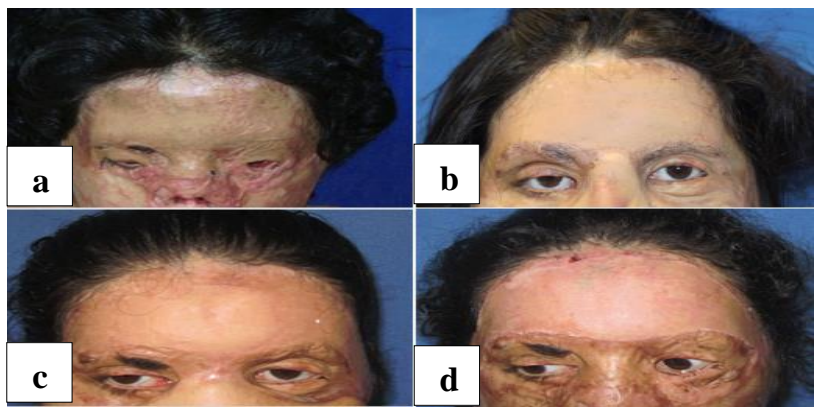

Figure 4: Results of post burn scar face - forehead (a) preoperative, (b) 6 weeks postoperative, (c) 6 months postoperation, and (d) 2 years post-operative. 


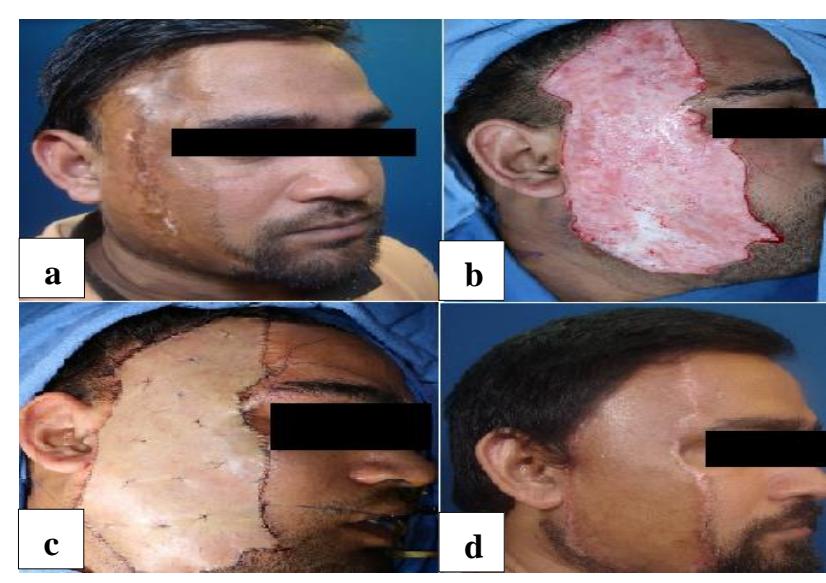

Figure 5: Results of post burn scar right side face (a) preoperative, (b) intraoperative - post excision of scar, (c) intraoperative - after application of graft, and (d) 4 months post-operative.

\section{DISCUSSION}

Tissue expansion is a technique that gradually expands an area of normal pliable skin in order to satisfy the requirement to cover the defect after excision of the burn or post-traumatic scar and contractures.,

Indications for tissue expansion include: limited availability of normal tissue, reconstruction of cosmetic areas such as the head and neck and breast, and reconstructed site requires expanded skin matching the burned area in terms of color, consistency, elasticity, pliability, presence of hair, and sensate properties.

In our series, one patient had limited donor area, 3 patients required reconstruction of cosmetic areas such as face and 3 patients required good pliable skin with presence of hair and sensate properties for limb reconstruction.

The objectives for reconstruction of post-burn sequelae and post-traumatic scarring include functional and aesthetic outcome. Good aesthetic results can be obtained by skin graft or flap. ${ }^{6-8}$ There are various complications reported related to tissue expanders. A 10-year review of tissue expansion procedures used in 82 burn patients identified complications such as expander exposure $(50 \%)$, infection (24\%), and malfunction of the expander (13\%). ${ }^{9}$ A retrospective analysis of 102 tissue expanders in 57 burn patients reported total failure rate of $7.8 \%$ (8/102 procedures) highest at the head $(20 \%)$ and with higher volume of expander $(400$ and $800 \mathrm{ml}) .{ }^{10,11}$ In our study none of the patients had complications related to the expanders. Rectangular expanders increase expansion surface compared to round expanders. ${ }^{9}$ In our study crescent shaped expanders were used as those shapes were available with us and a good amount of expanded skin was obtained.

Full-thickness skin grafts minimizes the wound contraction in multiple species due to the biological behavior of the graft and wound bed. ${ }^{12,13}$ For this reason, EFTSGs are utilized for the reconstruction of defect to produce a functionally or aesthetically favorable result. ${ }^{14}$ In our study the expanded full thickness graft was thin and closely matched in color to recipient area. Patients consent was taken during selection of the donor area. Patients were satisfied with the result of color match and cosmesis. There was no donor site morbidity noted and in all cases the donor site was closed primarily and it healed well.

\section{CONCLUSION}

The EFTSGs is a suitable solution to repair effectively scar and scar contractures due to excellent cosmetic and functional recovery. It is one of the viable and simple option in patient with limited (normal) donor area available for reconstruction. With this, one may get away from more complex microvascular flap surgeries which requires skilled expertise and special set up.

Funding: No funding sources Conflict of interest: None declared Ethical approval: Not required

\section{REFERENCES}

1. Huang T, Dibildox M. Chapter 51- The use of skin grafts, skin flaps and tissue expansion in burn deformity reconstruction. In: Herndon DN, editor. Total Burn Care. 2012;581-90.

2. Engrav LH, Donelan MB. Acute care and reconstruction of facial burns. In: Mathes $S$, Hentz V, editors. Textbook of Plastic Surgery. 2nd edition. Saunders Elsevier: Philadelphia. 2006;45-77.

3. Foyatier JL, Comparin JP, Masson CL. Skin flaps and expanded full-thickness skin grafts. Indications in the repair of burn sequelae. Ann Chir Plast Esthet. 1996;4:511-32.

4. Gil T, Metanes I, Aman B, Taran A, Mayblum S, Izhak T, et al. Six tissue expansion sessions of the scalp for reconstruction of post-burn alopecia. J Burn Care Res. 2008;29:390.

5. Di Mascio D, Castagnetti F, Mazzeo F, Caleffi E, Dominici C. Overexpansion technique in burn scar management. Burns. 2006;32:490.

6. Neuman Z, Wexler MR. Reconstruction of facila burns. In: Feller I, Grabb WC, editor. Reconstruction and Rehabilitation of Burned patient. Universtity of Michigan Press, Ann Arbor, Michigan. 2018;10-5.

7. Yeong EK, Chen MT, Mann R: Facial Mutilation after assault with chemical: 15 cases and literature review. J Burn Care Rehabil. 1997;18:234-17.

8. Feldman JJ. Facial resurfacing: The single sheet concept. In: Mc Carthy JG, editor. Plastic Surgery. W. B. Saunders, Philadelphia. 2010;327-42.

9. Cunha MS, Nakamoto HA, Herson MR, Faes JC, Gemperli R, Ferreira MC. Tissue expander complications in plastic surgery: a 10-year experience. Rev Hosp Clin Fac Med Sao Paulo. 2002;57:9. 
10. Bozkurt A, Groger A, O'Dey D, Vogeler F, Piatkowski A, Fuchs PCh, Pallua N. Retrospective analysis of tissue expansion in reconstructive burn surgery: evaluation of complication rates. Burns. 2008;34:1113.
Cite this article as: Ghag NV, Aggarwal A, Singh H, Singh S, Mahendru S, Brajesh V, Khazanchi R, Kothari U. Expanded full thickness skin graft to repair scar and scar contractures: a descriptive case series. Int Surg J 2020;7:3778-81. 